\title{
Influence of voxel size on micro-CT analysis of debris after root canal preparation
}

\author{
Jáder Camilo PINTO(a) \\ Fernanda Ferrari Esteves \\ TORRES(a) \\ Airton Oliveira SANTOS \\ JUNIOR(a) iD \\ Karina Ines Medina Carita \\ TAVARES(a) iD $^{(a)}$ \\ Juliane Maria \\ GUERREIRO-TANOMARU(a) \\ Mario TANOMARU-FILHO(a) \\ (a) Universidade Estadual Paulista - Unesp, \\ School of Dentistry, Department of \\ Restorative Dentistry, Araraquara, SP, Brazil.
}

Declaration of Interests: The authors certify that they have no commercial or associative interest that represents a conflict of interest in connection with the manuscript.

Corresponding Author:

Dr. Mario Tanomaru-Filho

E-mail: tanomaru@uol.com.br

https://doi.org/10.1590/1807-3107bor-2021.vol35.0008

Submitted: April 7, 2020

Accepted for publication: July 16, 2020

Last revision: August 24, 2020

\begin{abstract}
The aim of this study was to assess the influence of micro-computed tomography (micro-CT) voxel size on the evaluation of debris accumulation after passive ultrasonic irrigation (PUI) in curved root canals prepared with rotary nickel-titanium files. Mesial root canals $(n=24)$ of mandibular molars with curvature between $25^{\circ}$ and $35^{\circ}$ were prepared using ProDesign Logic 30/.05 (PDL) or HyFlex EDM 25/.08 (HEDM). PUI was performed after root canal preparation of all root canals. The specimens were scanned using high-resolution $(5 \mu \mathrm{m}$ voxel size) micro-CT imaging before and after experimental procedures. The percentage of debris was analyzed in the middle and apical thirds using images with 5, 10 and $20 \mu \mathrm{m}$ voxel sizes. Data were compared using unpaired and paired Student's t-test, ANOVA and Tukey's statistical tests $(\alpha=0.05)$. There were no differences among the debris analyses performed at different voxel sizes $(5,10$ and $20 \mu \mathrm{m})(\mathrm{p}>0.05)$. The percentage of debris was similar between the root canals prepared by PDL and HEDM before and after PUI ( $p>0.05$ ). In both groups, the percentage of debris decreased in the middle third after PUI $(p<0.05)$. Within the limitations of this ex vivo study, it can be concluded that the voxel sizes evaluated did not have a significant impact on the analysis of accumulated debris. However, the results showed a tendency for detection of more debris in the analysis performed using a lower voxel size. PUI decreased the debris accumulation in the middle third of curved root canals.
\end{abstract}

Keywords: Root Canal Preparation; Dental Pulp Cavity; Dental Instruments; X-Ray Microtomography; Ultrasonic Therapy.

\section{Introduction}

The aim of root canal treatment is to prevent apical periodontitis, by eliminating microorganisms from the root canal system. ${ }^{1}$ However, hard tissue debris is deposited on root canal walls after root canal preparation. ${ }^{2}$ The presence of debris in the root canal makes disinfection difficult, ${ }^{2,3}$ and decreases sealer adhesion to dentinal tubules. ${ }^{4}$ Paque et al. ${ }^{2}$ developed a method to view and analyze accumulated hard tissue debris in root canals using micro-computed tomography (micro-CT). Since then, micro-CT imaging has been used to evaluate debris accumulation. $5,6,7,8,9$

However, micro-CT analysis can be influenced by many factors, such as different scan settings, image resolutions and ring artifacts. ${ }^{10}$ Different 
micro-CT acquisition resolutions are used to analyze debris accumulation, using scanning voxel sizes of $9 \mu \mathrm{m},{ }^{5,7} 14 \mu \mathrm{m}^{8,11}, 18 \mu \mathrm{m},{ }^{6,12}$ and up to $20 \mu \mathrm{m} .^{2}$ The different means of image acquisition and image evaluation make it difficult to discuss results and compare different studies..$^{10}$ A smaller voxel size is ideal for micro-CT analysis, ${ }_{13}^{13}$ however, high-resolution scans require longer acquisition time, and generate large data sets.

New mechanized heat-treated nickel and titanium (NiTi) instruments have been proposed especially for centralized preparation in curved root canals. ${ }^{5,14}$ ProDesign Logic (PDL) (Easy Equipamentos Odontológicos, Belo Horizonte, MG, Brazil) manufactures NiTi instruments submitted to a heat treatment and featuring a controlled memory (CM), with improved flexural resistance. ${ }^{15}$ Hyflex EDM HEDM (Coltène/Whaledent, Allstätten, Switzerland) also makes heat-treated CM instruments, and offers a surface treatment, called electro-discharge machining (EDM). ${ }^{16}$ This manufacturing process improves the mechanical properties of HEDM files. ${ }^{17}$ These files maintain their integrity after multiple uses, and are associated with high resistance to cyclic fatigue. ${ }^{18}$

However, previous studies have observed large amounts of accumulated debris in root canals after preparation with mechanized NiTi instruments. ${ }^{4,5,7}$ Final irrigation protocols, such as passive ultrasonic irrigation (PUI), have been proposed to improve the cleaning of root canals. ${ }^{4,7}$ Irrisonic (Helse Ultrasonic, Santa Rosa de Viterbo, SP, Brazil) is an ultrasonic tip indicated for performing PUI. It is made of stainless steel with a size $20 / .01$ file. ${ }^{19}$ Ultrasonic activation with Irrisonic promoted greater reduction in microbial load within root canals. ${ }^{20}$

To the best of our knowledge, no studies have been performed to date that evaluate the influence of voxel size on the analysis of debris accumulation after root canal preparation. Therefore, the aim of this study was to assess the influence of voxel size in micro-CT evaluation of debris accumulation after PUI application in curved root canals prepared with PDL or HEDM. The first null hypothesis was that there would be no differences among the analyses performed at different voxel sizes $(5,10$ and $20 \mu \mathrm{m})$. The second null hypothesis was that PUI would not promote a decrease in the percentage of debris after preparation with PDL or HEDM.

\section{Methodology}

All the procedures were approved by the ethics committee (CEP no. 64736116.4.0000.5416). Human mandibular first and second molars previously stored in $0.1 \%$ thymol solution at $5{ }^{\circ} \mathrm{C}$ were used. The inclusion criteria consisted of the configuration of two independent mesial root canals according to the Vertucci type IV classification, ${ }^{21}$ angle of curvature between $25^{\circ}$ and $35^{\circ}$, in accordance with the Schneider method, ${ }^{22}$ and radius of curvature smaller than $10 \mathrm{~mm}$, following the Pruett method, ${ }^{23}$ in addition to complete apical formation, and absence of root fractures, calcifications or internal resorptions. These criteria were confirmed by radiographing the specimens using a digital system (RVG 6100; Kodak Dental Systems, NY) and a micro-CT device (SkyScan 1276; BrukermicroCT, Kontich, Belgium). The first scanning was performed at low-resolution ( $35-\mu \mathrm{m}$ voxel size) under the following settings: copper and aluminum filters, 87-millisecond exposure time, frame averaging of 3 , $180^{\circ}$ rotation around the vertical axis, rotational step of $0.5^{\circ}$ at $80 \mathrm{kV}$ and $300 \mu \mathrm{A}$.

A total of twelve roots were selected, totaling twenty-four root canals, including the mesiobuccal and mesiolingual canals of each root. The root canals were randomly divided into two experimental groups $(n=12)$, using stratified random sampling, considering the preoperative root canal volume. Six mesiobuccal canals and six mesiolingual canals were used in each group. The root length was standardized at $18 \mathrm{~mm}$, with a tolerance of $\pm 1 \mathrm{~mm}$ of discrepancy. The specimens were embedded in condensation silicone (Oranwash, Zhermack, Badia Polesine, Italy) to simulate the periodontal ligament.

\section{Root canal preparation}

Conventional access cavities were performed, and the root canals were explored with a size \#10 K-file (Dentsply Sirona Endodontics, Ballaigues, Switzerland) up to the apical foramen. The working length (WL) was established $1 \mathrm{~mm}$ short of the apical foramen, and confirmed by a digital radiograph. Afterwards, 
a trained operator instrumented all the specimens with an operating microscope (MC-M1232, DF Vasconcellos, Valença, Brazil) at 13X magnification, using an endodontic motor (VDW Silver, VDW, Munich, Germany).

PDL group: Instrumentation with PDL. The 30/.01 file was used in continuous rotation at $350 \mathrm{rpm}$ speed and $1 \mathrm{Ncm}$ torque, using in-and-out movements up to the working length. Then, the $30 / .05$ file was used at $600 \mathrm{rpm}$ speed and $4 \mathrm{Ncm}$ torque.

HEDM group: Instrumentation with HEDM. The 10/.05 file was used in continuous rotation at $300 \mathrm{rpm}$ speed and $1.8 \mathrm{Ncm}$ torque, using in-and-out movements up to the working length. Then, the HEDM 25/.08 file was used at $500 \mathrm{rpm}$ speed and $2.5 \mathrm{Ncm}$ torque.

Root canal irrigation was performed with $5 \mathrm{~mL}$ of $2.5 \%$ sodium hypochlorite $(\mathrm{NaOCl})$, using a $30 \mathrm{G}$ sidevented needle (NaviTip, Ultradent Products, South Jordan, UT) adapted to a $5 \mathrm{~mL}$ syringe (Ultradent Products) placed $2 \mathrm{~mm}$ short of the working length.

\section{Passive ultrasonic irrigation (PUI)}

The Irrisonic ultrasonic tip was activated in an Ultrawave XS ultrasonic device (Ultradent, South Jordan, USA) using a power of $10 \%$ and frequency of $50 \mathrm{~Hz}$, according to the manufacturer's recommendation. The ultrasonic tips were positioned $2 \mathrm{~mm}$ short of the working length and used in in-and-out movements to avoid contact with the root canal walls. The irrigant solution was delivered into the root canals, and the ultrasonic activation was performed using three cycles of 20 seconds each, with $2.5 \% \mathrm{NaOCl}$ in the first and third cycles, and $17 \%$ EDTA in the second cycle. A 2-mL aliquot of irrigation solution was used in each cycle, totalizing $4 \mathrm{~mL}$ of $\mathrm{NaOCl}$ and $2 \mathrm{~mL}$ of EDTA. The final irrigation used $5 \mathrm{~mL}$ of distilled water.

\section{Micro-CT analysis}

The specimens were scanned at high-resolution (5- $\mu \mathrm{m}$ voxel size) before and after instrumentation, and after PUI application, under the following settings: copper filter, $180^{\circ}$ rotation around the vertical axis and rotational step of $0.2^{\circ}$ at $100 \mathrm{kV}$ and $100 \mu \mathrm{A}$. The images were reconstructed using NRecon software
(V1.6.10.4; Bruker, Belgium), and superimposed by geometric alignment using DataViewer software (V.1.5.1, Bruker, Belgium). Representative images were performed with models obtained from CTVol software (v.2.3.1.0; Bruker-microCT). The quantitative analysis was performed using CTAn software (V.1.14.4, Bruker, Belgium). Original images were resized isotropically to perform comparative analyses among the different voxel sizes. Images at 10 and $20 \mu \mathrm{m}$ were obtained and used for quantitative analysis. This was achieved by resizing the previously scanned $5-\mu \mathrm{m}$ images by 2 and 4, respectively, using CTAn software, when loading the dataset previously superimposed in DataViewer software. ${ }^{24}$

The analyses were performed in the middle and apical thirds of the roots, considering $3 \mathrm{~mm}$ for each third. Preoperative volume, volume of the prepared canal, and volume of debris after preparation were obtained. Based on these values, the percentage of debris (\% Debris) was calculated using the following formula:

$$
\% \text { Debris }=\frac{\text { Volume of debris } \times 100}{\text { Volume of prepared canal }}
$$

\section{Statistical analysis}

The data obtained were submitted to the Shapiro-Wilks normality test, and all the data presented normal distribution. Regarding the analyses between the groups, the no-paired t-test was used, and regarding debris quantification before and after PUI application, the paired t-test was applied. As for the analysis among images with different voxel size, ANOVA and Tukey's tests were performed. The level of significance was set at $\mathrm{p}<0.05$.

\section{Results}

There were no differences among the debris analyses performed at different voxel sizes $(5,10$ and $20 \mu \mathrm{m})(\mathrm{p}>0.05)$. The percentage of debris was similar between the root canals prepared by PDL and HEDM before and after PUI application ( $p>0.05)$. In both groups, the percentage of debris decreased after PUI activation in the middle third $(\mathrm{p}<0.05)$ (Table). Figure shows 3D models representing debris accumulation in root canals after preparation with PDL and with HEDM, before and after PUI application. 
Table. Means and standard deviations of percentage of debris analyzed at different voxel sizes in curved root canals prepared with ProDesign Logic 30/.05 (PDL) and HyFlex EDM 25/.08 (HEDM) before and after passive ultrasonic irrigation (PUI).

\begin{tabular}{ccccccc}
\hline \multirow{2}{*}{ Variable } & \multicolumn{2}{c}{$5 \mu \mathrm{m}$} & \multicolumn{2}{c}{$10 \mu \mathrm{m}$} & $20 \mu \mathrm{m}$ \\
\cline { 2 - 7 } & Before PUI & After PUI & Before PUI & After PUI & Before PUI & After PUI \\
\hline PDL & & & & & & \\
Middle & $3.08 \pm 2.27^{a}$ & $0.91 \pm 0.33^{b}$ & $2.62 \pm 1,65^{a}$ & $0.84 \pm 0.32^{b}$ & $2.24 \pm 1.47^{a}$ & $0.79 \pm 0.34^{b}$ \\
Apical & $5.07 \pm 2.53^{a}$ & $2.68 \pm 1.23^{a}$ & $4.64 \pm 2.28^{a}$ & $2.55 \pm 1.21^{a}$ & $4.39 \pm 2.56^{a}$ & $2.38 \pm 1.17^{a}$ \\
HEDM & & & & & & \\
Middle & $3.65 \pm 2.03^{a}$ & $1.44 \pm 0.88^{b}$ & $3.43 \pm 0.09^{a}$ & $1.32 \pm 1.68^{b}$ & $2.79 \pm 2.32^{a}$ & $1.05 \pm 0.54^{b}$ \\
Apical & $5.77 \pm 2.94^{a}$ & $3.98 \pm 0.98^{a}$ & $5.77 \pm 3.03^{a}$ & $3.67 \pm 0.84^{a}$ & $5.25 \pm 2.96^{a}$ & $3.37 \pm 0.91^{a}$ \\
\hline
\end{tabular}

Different superscript lowercase letters on the same line indicate significant differences detected among the percentages of debris before and after using PUI $(p<0.05)$.

Before PUI

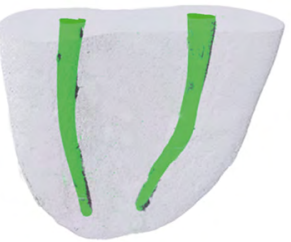

Before PUI

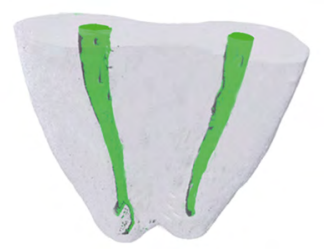

After PU

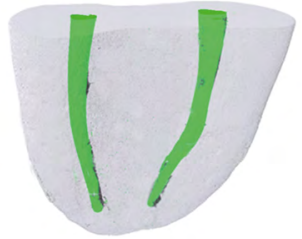

After PUI

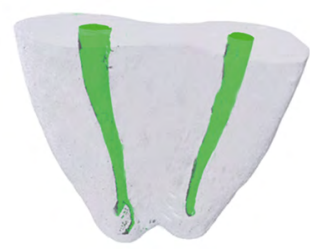

Figure. $3 \mathrm{D}$ reconstructions of images with $5-\mu \mathrm{m}$ voxel size of middle and apical thirds of mesial roots of mandibular molars prepared by ProDesign Logic and HyFlex EDM before and after PUI, showing debris accumulation in black.

\section{Discussion}

Accumulation of debris after root canal preparation can impair disinfection of the root canal system. ${ }^{25}$ Micro-CT has been used in recent studies to evaluate debris accumulation, owing to its high accuracy and high spatial resolution. ${ }^{25,6,67,8}$ The first null hypothesis was accepted, because similar results were observed for root debris, using different voxel size analyses.

The voxel size can affect the quality of the images, and consequently that of the analyses performed. ${ }^{10,26}$ Previous studies have observed that the analysis of trabecular bone structure ${ }^{13,24,27,28}$ and voids in filled root canals ${ }^{29}$ is significantly affected by micro-CT scanning voxel size. However, larger voxels

do not always mean lower diagnostic accuracy. ${ }^{30,31}$ Studies that have evaluated the influence of voxel size in diagnoses using cone beam computed tomography images of root fracture are conflicting. ${ }^{31,32,33}$ Whereas a previous investigation showed significantly higher detection of vertical root fractures in images with smaller voxel size, ${ }^{32}$ Özer $^{33}$ reported that there were no significant differences in the diagnostic accuracy of root fracture among cone beam computed tomography images captured with different voxel sizes.

Higher scan resolution is a favorable feature in performing micro-CT analysis. However, scans with higher voxel size can be obtained faster and generate smaller data sets. ${ }^{13}$ Voxel size was the only variable evaluated in the present study, as done in previous methodological models. ${ }^{24,27,28}$ The samples were scanned at $5 \mu \mathrm{m}$ and the reconstructed images were resized by 2 and 4 to acquire images with 10 and $20 \mu \mathrm{m}$ voxel sizes. ${ }^{24}$ The new values produced for the images resized to larger voxel sizes represent the average of previous voxels, leading to a decrease in the accuracy of the image. ${ }^{24,27}$ Although this method could be considered a limitation of the current study, it actually allowed accurate comparisons among the same regions of interest ${ }^{24}$. In brief, by enreasing the voxel size with the software, we could save the time required to run a new micro-CT scan. Moreover, the smaller voxel size used during the scanning procedure may be considered the gold standard to determine the level of accuracy under limited resolution scenarios. ${ }^{27,28}$ However, although the voxel size may have significant effects on the results, ${ }^{13,29,34}$ it is not the only factor influencing spatial resolution of the micro-CT image. ${ }^{10,27}$ The spatial resolution 
also depends on mean absorption of the sample, detector noise, reconstruction algorithm, $X$-ray focal spot size and shape, detector aperture, and scanner geometry. ${ }^{10}$ Within the limitations of the present study, our findings suggest that a $20-\mu \mathrm{m}$ voxel size may be used for debris evaluation, thus representing a cost reduction factor for further research.

Although the analyses of the different voxel sizes did not produce significative differences in the results, there was a tendency to have a higher percentage of debris in analyses performed at a smaller voxel size than those performed at a larger voxel size. Considering that the statistical significance is dependent on the sample variance, ${ }^{35}$ the larger standard deviation of the results may have contributed to the statistical similarities among the analyses performed at different voxel sizes. Several studies that have evaluated debris accumulations by micro-CT have also shown a large standard deviation $^{2,4,7,8,11,12}$ or non-normal distribution of data. ${ }^{5,6}$ Even using methods that improve the sample selection criteria, such as micro-CT analyses for tooth selection and sample randomization, ${ }^{5}$ it is difficult to standardize the debris accumulated in each root canal after its preparation.

PUI is an irrigation protocol that uses acoustic energy-promoting hydrodynamic agitation of the liquid. ${ }^{36}$ The reduction in root canal debris after performing PUI has been reported by several studies. ${ }^{4,711,37}$ As expected, in the present study, PUI decreased the percentage of debris in the middle third after preparation with PDL and HEDM. However, PUI did not reduce the percentage of debris in the apical third. In the present investigation, Irrisonic was inserted up to $2 \mathrm{~mm}$ short of the $\mathrm{WL}^{4,7,71}$ and promoted a limited effect on the apical third of the root canal. In addition, the largest width of the cervical root canal allows it to be cleaned more effectively, ${ }^{38}$ leading to better circulation and effect of the irrigating solution. ${ }^{39,40}$ Moreover, a previous study showed that activation of the irrigating solution using PUI promoted less effective debris removal in the apical third than a reciprocating system for final irrigation. ${ }^{38}$

\section{Conclusions}

Within the limitations of the present study, it can be concluded that the voxel sizes evaluated did not have a significant impact on the analysis of accumulated debris. However, the results showed a tendency of more debris detection in analyses performed at a lower voxel size. PUI reduced the debris accumulation in the middle third of curved root canals.

\section{Acknowledgments}

This study was supported in part by the Coordenação de Aperfeiçoamento de Pessoal de Nível Superior, Brasil (CAPES), Funding Code 001, and was fully supported by the São Paulo Research Foundation - FAPESP [grant numbers 2017/19049-0 and 2018/19665-6 -0].

\section{References}

1. Azim AA, Griggs JA, Huang GT. The Tennessee study: factors affecting treatment outcome and healing time following nonsurgical root canal treatment. Int Endod J. 2016 Jan;49(1):6-16. https://doi.org/10.1111/iej.12429

2. Paqué F, Laib A, Gautschi H, Zehnder M. Hard-tissue debris accumulation analysis by high-resolution computed tomography scans. J Endod. 2009 Jul;35(7):1044-7. https://doi.org/10.1016/i.joen.2009.04.026

3. Siqueira JF Jr, Pérez AR, Marceliano-Alves MF, Provenzano JC, Silva SG, Pires FR, et al. What happens to unprepared root canal walls: a correlative analysis using micro-computed tomography and histology/scanning electron microscopy. Int Endod J. 2018 May;51(5):501-8. https://doi.org/10.1111/iej.12753

4. Freire LG, Iglecias EF, Cunha RS, Santos M, Gavini G. Micro-Computed Tomographic Evaluation of Hard Tissue Debris Removal after Different Irrigation Methods and Its Influence on the Filling of Curved Canals. J Endod. 2015 Oct;41(10):1660-6. https://doi.org/10.1016/i.joen.2015.05.001

5. Pinto JC, Pivoto-João MM, Espir CG, Ramos ML, Guerreiro-Tanomaru JM, Tanomaru-Filho M. Micro-CT evaluation of apical enlargement of molar root canals using rotary or reciprocating heat-treated NiTi instruments. J Appl Oral Sci. 2019 Aug;27:e20180689. https://doi.org/10.1590/1678-7757-2018-0689 
6. Espir CG, Nascimento-Mendes CA, Guerreiro-Tanomaru JM, Freire LG, Gavini G, Tanomaru-Filho M. Counterclockwise or clockwise reciprocating motion for oval root canal preparation: a micro-CT analysis. Int Endod J. 2018 May;51(5):541-8. https://doi.org/10.1111/iej.12776 PMID:28375575

7. Leoni GB, Versiani MA, Silva-Sousa YT, Bruniera JF, Pécora JD, Sousa-Neto MD. Ex vivo evaluation of four final irrigation protocols on the removal of hard-tissue debris from the mesial root canal system of mandibular first molars. Int Endod J. 2017 Apr;50(4):398-406. https://doi.org/10.1111/iej.12630

8. De-Deus G, Marins J, Silva EJ, Souza E, Belladonna FG, Reis C, et al. Accumulated hard tissue debris produced during reciprocating and rotary nickel-titanium canal preparation. J Endod. 2015 May;41(5):676-81. https://doi.org/10.1016/i.joen.2014.11.028

9. Sousa-Neto MD, Silva-Sousa YC, Mazzi-Chaves JF, Carvalho KK, Barbosa AF, Versiani MA, et al. Root canal preparation using micro-computed tomography analysis: a literature review. Braz Oral Res. 2018 Oct;32 suppl 1:e66. https://doi.org/10.1590/1807-3107bor-2018.vol32.0066

10. Bouxsein ML, Boyd SK, Christiansen BA, Guldberg RE, Jepsen KJ, Müller R. Guidelines for assessment of bone microstructure in rodents using micro-computed tomography. J Bone Miner Res. 2010 Jul;25(7):1468-86. https://doi.org/10.1002/jbmr.141

11. De-Deus G, Belladonna FG, Zuolo AS, Perez R, Carvalho MS, Souza EM, et al. Micro-CT comparison of XP-endo Finisher and passive ultrasonic irrigation as final irrigation protocols on the removal of accumulated hard-tissue debris from oval shaped-canals. Clin Oral Investig. 2019 Jul;23(7):3087-93. https://doi.org/10.1007/s00784-018-2729-y

12. Espir CG, Nascimento-Mendes CA, Guerreiro-Tanomaru JM, Cavenago BC, Hungaro Duarte MA, Tanomaru-Filho M. Shaping ability of rotary or reciprocating systems for oval root canal preparation: a micro-computed tomography study. Clin Oral Investig 2018 Dec;22(9):3189-94. https://doi.org/10.1007/s00784-018-2411-4

13. Christiansen BA. Effect of micro-computed tomography voxel size and segmentation method on trabecular bone microstructure measures in mice. Bone Rep. 2016 May;5:136-40. https://doi.org/10.1016/i.bonr.2016.05.006

14. Pinheiro SR, Alcalde MP, Vivacqua-Gomes N, Bramante CM, Vivan RR, Duarte MA, et al. Evaluation of apical transportation and centring ability of five thermally treated NiTi rotary systems. Int Endod J. 2018 Jun;51(6):705-13. https://doi.org/10.1111/iej.12881

15. de Menezes SE, Batista SM, Lira JO, Monteiro GQM. Cyclic fatigue resistance of waveone gold, prodesign $r$ and prodesign logic files in curved canals in vitro. Iran Endod J. 2017;12(4):468-73. https://doi.org/10.22037/iej.v12i4.17494

16. Pedullà E, Genovesi F, Rapisarda S, La Rosa GR, Grande NM, Plotino G, et al. Effects of 6 Single-File Systems on Dentinal Crack Formation. J Endod. 2017 Mar;43(3):456-61. https://doi.org/10.1016/i.joen.2016.10.038

17. Iacono F, Pirani C, Generali L, Bolelli G, Sassatelli P, Lusvarghi L, et al. Structural analysis of HyFlex EDM instruments. Int Endod J. 2017 Mar;50(3):303-13. https://doi.org/10.1111/iej.12620

18. Pirani C, lacono F, Generali L, Sassatelli P, Nucci C, Lusvarghi L, et al. HyFlex EDM: superficial features, metallurgical analysis and fatigue resistance of innovative electro discharge machined NiTi rotary instruments. Int Endod J. 2016 May;49(5):483-93. https://doi.org/10.1111/iej.12470

19. Reis S, Cruz VM, Duarte MAH, Bueno CES, Vivan RR, Pelegrine RA, et al. Volumetric analysis of irrigant extrusion in immature teeth after different final agitation techniques. J Endod. 2020 May;46(5):682-7. https://doi.org/10.1016/i.joen.2020.01.014

20. Aveiro E, Chiarelli-Neto VM, de-Jesus-Soares A, Zaia AA, Ferraz CC, Almeida JF, et al. Efficacy of reciprocating and ultrasonic activation of $6 \%$ sodium hypochlorite in the reduction of microbial content and virulence factors in teeth with primary endodontic infection. Int Endod J. 2020 May;53(5):604-18. https://doi.org/10.1111/iej.13261

21. Vertucci FJ. Root canal anatomy of the human permanent teeth. Oral Surg Oral Med Oral Pathol. 1984 Nov;58(5):589-99. https://doi.org/10.1016/0030-4220(84)90085-9

22. Schneider SW. A comparison of canal preparations in straight and curved root canals. Oral Surg Oral Med Oral Pathol. 1971 Aug;32(2):271-5. https://doi.org/10.1016/0030-4220(71)90230-1

23. Pruett JP, Clement DJ, Carnes DL Jr. Cyclic fatigue testing of nickel-titanium endodontic instruments. J Endod. 1997 Feb;23(2):77-85. https://doi.org/10.1016/S0099-2399(97)80250-6

24. Isaksson H, Töyräs J, Hakulinen M, Aula AS, Tamminen I, Julkunen P, et al. Structural parameters of normal and osteoporotic human trabecular bone are affected differently by microCT image resolution. Osteoporos Int. 2011 Jan;22(1):167-77. https://doi.org/10.1007/s00198-010-1219-0

25. Haapasalo M, Qian W, Portenier I, Waltimo T. Effects of dentin on the antimicrobial properties of endodontic medicaments. J Endod. 2007 Aug;33(8):917-25. https://doi.org/10.1016/j.joen.2007.04.008

26. Dalili Z, Taramsari M, Mousavi Mehr SZ, Salamat F. Diagnostic value of two modes of cone-beam computed tomography in evaluation of simulated external root resorption: an in vitro study. Imaging Sci Dent. 2012 Mar;42(1):19-24. https://doi.org/10.5624/isd.2012.42.1.19

27. Kim DG, Christopherson GT, Dong XN, Fyhrie DP, Yeni YN. The effect of microcomputed tomography scanning and reconstruction voxel size on the accuracy of stereological measurements in human cancellous bone. Bone. 2004 Dec;35(6):1375-82. https://doi.org/10.1016/i.bone.2004.09.007 
28. Sode M, Burghardt AJ, Nissenson RA, Majumdar S. Resolution dependence of the non-metric trabecular structure indices. Bone. 2008 Apr;42(4):728-36. https://doi.org/10.1016/i.bone.2007.12.004

29. Orhan K, Jacobs R, Celikten B, Huang Y, de Faria Vasconcelos K, Nicolielo LF, et al. Evaluation of Threshold Values for Root Canal Filling Voids in Micro-CT and Nano-CT Images. Scanning. 2018 Jul;2018:9437569. https://doi.org/10.1155/2018/9437569

30. Choi JW. Factors affecting modulation transfer function measurements in cone-beam computed tomographic images. Imaging Sci Dent. 2019 Jun;49(2):131-7. https://doi.org/10.5624/isd.2019.49.2.131

31. Güngör E, Doğan MS. Reliability and accuracy of cone-beam computed tomography voxel density and linear distance measurement at different voxel sizes: A study on sheep head cadaver. J Dent Sci. 2017 Jun;12(2):145-50. https://doi.org/10.1016/i.jds.2016.11.004

32. Bragatto FP, Iwaki Filho L, Kasuya AV, Chicarelli M, Queiroz AF, Takeshita WM, et al. Accuracy in the diagnosis of vertical root fractures, external root resorptions, and root perforations using cone-beam computed tomography with different voxel sizes of acquisition. J Conserv Dent. 2016 Nov-Dec;19(6):573-7. https://doi.org/10.4103/0972-0707.194029

33. Özer SY. Detection of vertical root fractures by using cone beam computed tomography with variable voxel sizes in an in vitro model. J Endod. 2011 Jan;37(1):75-9. https://doi.org/10.1016/i.joen.2010.04.021

34. Yamamoto-Silva FP, Siqueira CFO, Silva MA, Fonseca RB, Santos AA, Estrela C, et al. Influence of voxel size on cone-beam computed tomography-based detection of vertical root fractures in the presence of intracanal metallic posts. Imaging Sci Dent. 2018 Sep;48(3):177-84. https://doi.org/10.5624/isd.2018.48.3.177

35. Van Calster B, Steyerberg EW, Collins GS, Smits T. Consequences of relying on statistical significance: some illustrations. Eur J Clin Invest. 2018 May;48(5):e12912. https://doi.org/10.1111/eci.12912

36. Sluis LW, Versluis M, Wu MK, Wesselink PR. Passive ultrasonic irrigation of the root canal: a review of the literature. Int Endod J. 2007 Jun;40(6):415-26. https://doi.org/10.1111/j.1365-2591.2007.01243.x

37. Bueno CR, Cury MT, Vasques AM, Sarmiento JL, Trizzi JQ, Jacinto RC, et al. Cleaning effectiveness of a nickeltitanium ultrasonic tip in ultrasonically activated irrigation: a SEM study. Braz Oral Res. 2019 Mar;33:e017. https://doi.org/10.1590/1807-3107bor-2019.vol33.0017

38. Kato AS, Cunha RS, Bueno CES, Pelegrine RA, Fontana CE, Martin AS. Investigation of the Efficacy of Passive Ultrasonic Irrigation Versus Irrigation with Reciprocating Activation: An Environmental Scanning Electron Microscopic Study. J Endod. 2016 Apr;42(4):659-63. https://doi.org/10.1016/i.joen.2016.01.016

39. Teixeira CS, Felippe MC, Felippe WT. The effect of application time of EDTA and NaOCl on intracanal smear layer removal: an SEM analysis. Int Endod J. 2005 May;38(5):285-90. https://doi.org/10.1111/i.1365-2591.2005.00930.x

40. Mendonça DH, Colucci V, Rached-Junior FJ, Miranda CE, Silva-Sousa YT, Silva SR. Effects of various irrigation/aspiration protocols on cleaning of flattened root canals. Braz Oral Res. 2015;29(1):1-9. https://doi.org/10.1590/1807-3107BOR-2015.vol29.0082 